\title{
Blend global analyses into the cyclic convective-scale data assimilation system to improve short-term QPF
}

\author{
Siou-Ying Jiang ${ }^{1,2}$, Jing-Shan Hong ${ }^{2, *}$, and Ben Jong-Dao Jou ${ }^{1}$ \\ ${ }^{I}$ Department of Atmospheric Sciences, National Taiwan University, Taipei City, Taiwan \\ ${ }^{2}$ Central Weather Bureau, Taipei City, Taiwan
}

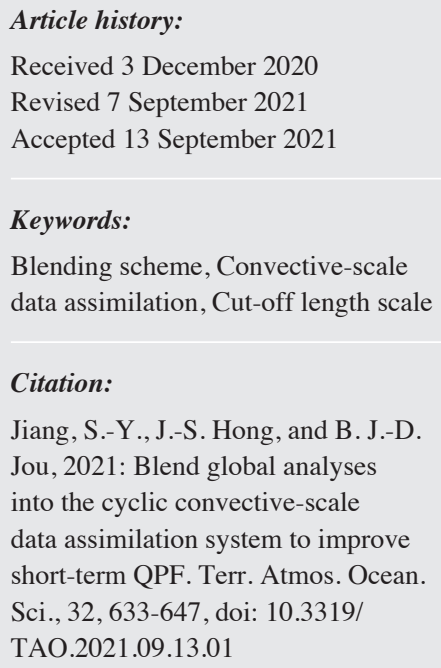

Citation:

Jiang, S.-Y., J.-S. Hong, and B. J.-D. Jou, 2021: Blend global analyses into the cyclic convective-scale data assimilation system to improve short-term QPF. Terr. Atmos. Ocean. Sci., 32, 633-647, doi: 10.3319/ TAO.2021.09.13.01

\begin{abstract}
In this study, we investigate the feasibility of using a blending scheme to combine global coarse-resolution analysis with a high-resolution limited-area model. By regularly introducing large-scale information, we intend to correct accumulated forecast error in a high-resolution model due to continuous data assimilation cycles. The impact of incorporating the blending scheme into three-dimensional variational (3DVAR) and local ensemble transform Kalman filter (LETKF) data assimilation systems are evaluated using a frontal rainband case. In this study, we aim to answer three questions: (1) Can including larger-scale information correct accumulated forecast error and improve model quantitative precipitation forecast (QPF) skill? (2) What is the optimal cut-off length scale (CLS) for the two systems? (3) Which prognostic variables are influential if we want to optimize model QPF skill by applying the blending technique on it? Results from 24 cycles with an hourly update reveal that incorporating the blending scheme successfully mitigates accumulated forecast error and improves model QPF skill for both systems. For this case, $600 \mathrm{~km}$ is the optimal CLS that most enhances model QPF. Also, blending large-scale water vapor to correct moisture field plays a key role in this case. Furthermore, the blending scheme imposes a larger impact in 3DVAR than that in LETKF. The reason is that the large-scale information is directly blended into the 3DVAR background which contains more convective-scale features while it is used to recenter the smoother LETKF ensemble mean. This results in smoothed blending analysis and could further aggravate model spin-up time in high-resolution forecast.
\end{abstract}

\section{INTRODUCTION}

Rapid-evolved convective-scale rainfall systems (Westra et al. 2014), which are often accompanied by extreme rainfall, have relatively low predictability compared with larger-scale systems. In particular, for regions with complex terrain, the model forecast skill for convective systems is especially limited (Hohenegger and Schär 2007; Yano et al. 2018). In order to increase the model forecast skill, it is important to improve initial condition accuracy, apply suitable model physics and increase model resolution (Sun et al. 2014). Among these, an accurate initial condition can significantly improve model short-term forecast accuracy. Several studies have demonstrated the success of data assimilation in the convective-scale forecast, including the use of

\footnotetext{
* Corresponding author

E-mail:rfs14@cwb.gov.tw
}

radar observations (Xiao et al. 2007; Xue et al. 2010; Bick et al. 2016; Ridal and Dahlbom 2017; Kong et al. 2018; Cheng et al. 2020; You et al. 2020), surface observations (Chen et al. 2020) and precipitable water vapor information obtained from the Global Navigation Satellite System (GNSS) zenith total delay observations (Yang et al. 2020).

However, it is still challenging to predict the intensity and location of convective systems accurately. First of all, the strong nonlinearity of convective systems causes rapid growth of forecast error. Model forecast error could result from imperfect dynamics, uncertainties in physical parameterization schemes, and prescribed lateral boundary conditions. Small-scale forecast error could propagate to large scales and therefore degrade the forecast accuracy (Cha and Lee 2009; Vincent and Hahmann 2015). Hence, for convective-scale data assimilation systems, it is critical to 
use rapid update cycles to correct model forecast error. For example, Miyoshi et al. (2016) selected a 30-second cycling frequency to assimilate phased-array radar observations and successfully captured the evolution of a severe convective system. However, the cycling strategy often leads to accumulated forecast error due to model spin-up caused by imbalanced dynamic and thermodynamic fields. Sun and Zhang (2008) pointed out that model QPF performance was decreased with increasing updated cycle frequency. In addition, it is difficult to correct model forecast error over datasparse areas. For example, the Taiwan island is surrounded by an ocean that is short of observations. In conclusion, the data assimilation alone may not be enough to correct the accumulated forecast error effectively.

Several approaches have been proposed to mitigate the accumulated forecast error. For instance, Tong et al. (2016) adopted a two-step assimilation strategy that assimilated conventional observation before radar data assimilation. This two-step assimilation strategy maintained both larger-scale and convective-scale features in the model analysis. Current operational convective-scale numerical weather prediction (NWP) systems such as the Rapid Refresh (RAP), the High-Resolution Rapid Refresh (HRRR), and the CONUSNAM (CONtiguous United States nest of North American Mesoscale system - convective-scale forecasting system) nest also used cloud analysis and radar-reflectivity-derived latent heat nudging techniques to introduce observed cloud and deep convection information into NWP models (Benjamin et al. 2016; Gustafsson et al. 2018). However, in an area without sufficient observations, the model forecast error accumulates during rapid update cycles and ultimately leads to an increase of forecast error and bias.

To mitigate accumulated forecast error, Yang (2005a, b) proposed a blending scheme that obtained an analysis by combining large-scale and finer-scale fields through an incremental spatial filtering technique. Using this blending scheme, Wang et al. (2014) demonstrated that this technique successfully reduced accumulated forecast error. Furthermore, Hsiao et al. (2015) combined large-scale patterns (wavelength $>1200 \mathrm{~km}$ ) of the NCEP global analysis with fine-scale structure (wavelength $<1200 \mathrm{~km}$ ) of a high-resolution regional model. They demonstrated that this blending technique not only removed systematic forecast error resulted from update cycles, but also improved the prediction of tropical cyclone track and rainfall over Taiwan island.

In this study, we aimed to investigate the impact of combining this blending scheme into the convective-scale data assimilation system, which had a horizontal resolution of $2 \mathrm{~km}$ and an update frequency of 1 hour. Although several studies had proven the benefits of implementing this blending technique into regional forecast systems, its impact on the convective-scale data assimilation system required further investigation due to its higher model resolution and update frequency. In this study, we used two convective- scale radar data assimilation systems currently operational in Central Weather Bureau (CWB). Both systems are based on the Weather Research and Forecasting (WRF) model with different data assimilation algorithms, one with threedimensional variational data assimilation (3DVAR; Barker et al. 2012) and the other with Local Ensemble Transform Kalman Filter (LETKF; Hunt et al. 2007; Yang et al. 2009; Tsai et al. 2014). This paper was organized as follows. Sections 2 and 3 are the experimental design and the results, respectively. A summary is presented in section 4 .

\section{EXPERIMENTAL DENSIGN}

\subsection{Radar Data Assimilation Systems}

Two radar data assimilation systems, one based on WRF 3DVAR (Barker et al. 2012) and the other used a 32-member LETKF (Hunt et al. 2007), were selected to investigate the impact of the blending scheme on the convective-scale model forecast. Both systems adopted hourly update cycles with boundary condition provided by NCEP GFS forecasts. Except for their different data assimilation techniques, both systems use WRF (Weather Research and Forecasting; Michalakes et al. 2001) model with an identical model configuration (Fig. 1). Identical to operational settings, the model used in this study had a $2 \mathrm{~km}$ horizontal resolution and 52 vertical levels with the model top at 20 $\mathrm{hPa}$. The model physics included Noah land surface model (Tewari et al. 2004), Goddard microphysical scheme (Tao et al. 2016), YSU PBL scheme (Hong et al. 2006), and RRTMG radiation scheme (Iacono et al. 2008).

In this study, radar radial velocity and reflectivity were assimilated every hour by selecting the volume scan that was closest, which had roughly 0 - 10 minutes difference, to the analysis time at each radar site. Here, four S-band radars (Fig. 1), including Wufenshan (RCWF), Hualien (RCHL), Chiku (RCCG), and Kenting (RCKT), were used in all experiments. For radial velocity and reflectivity observations, a set of hybrid scans constructed by Chang et al. (2009) was implemented to perform quality control. Due to the irregular radar data distribution in polar coordinates, appropriate data preprocessing was needed. For example, Liu et al. (2016) proposed the three-dimensional (3D) reflectivity mosaic in NCEP's data assimilation systems, which interpolated and composited the individual radar observations to the Cartesian coordinate system. Feng et al. (2020) suggested that the radial velocity observations applied the evenly spaced thinning method (ESTM) on the polar coordinate, obtaining the best data assimilation performance. In this study, in both the 3DVAR and LETKF systems, the radial velocity for individual radar was thinned to a rough resolution of $2 \mathrm{~km}$ in the original polar coordinate. The reflectivity was interpolated by the Adaptive Barnes method (Askelson et al. 2000) and composited to a Cartesian coordinate with a horizontal resolution of $2 \mathrm{~km}$ and $500 \mathrm{~m}$ in vertical. 


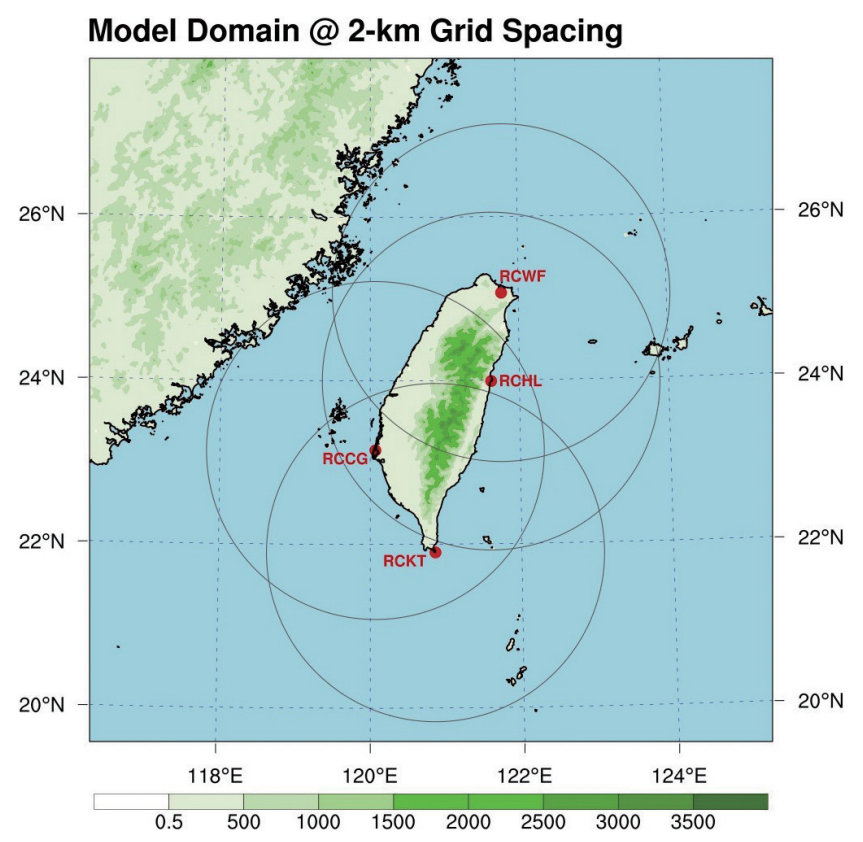

Fig. 1. The model domain, radar location, and radar coverage. The color shading is the terrain height (m) base on a 2-km model mesh.

The use of the observation variables and the strategy to update the analysis variables between the 3DVAR and LETKF systems were different. In summary,

- In 3DVAR, the reflectivity was assimilated through cloud control variables, including rainwater $\left(q_{r}\right)$, snow $\left(q_{s}\right)$, and graupel $\left(q_{g}\right)$ mixing ratio. The above hydrometer variables were retrieved as observations from reflectivity based on Gao and Stensrud (2012). For the assimilation of radial velocity, 3DVAR and LETKF systems both applied the same observation operator (Sun and Crook 1997). 3DVAR only updated the $\mathrm{x}$ and $\mathrm{y}$ components of wind $(u, v)$ and used them as control variables. Sun et al. (2016) demonstrated that the univariate $(u, v)$ control variable, denoted as the CV-option 7 in WRF 3DVAR, was more suitable for the convective scale since it produced an analysis with small-scale features. Also, the large-scale balance had less impact under the small temporal and spatial scale of convective systems.

- In LETKF, the reflectivity was directly used to correct only the $q_{r}, q_{s}$, and $q_{g}$ through its flow-dependent background error covariance. The reflectivity observation operator in LETKF was from Dowell et al. (2011), in which the intercept parameter and hydrometer density were defined based on the Goddard microphysical scheme (Tao et al. 2016). The radial velocity observations were only assimilated to update the three-dimensional velocity components $(u, v$, and $w)$, perturbation potential temperature $\left(\theta^{\prime}\right)$, and water vapor mixing ratio $\left(q_{v}\right)$. Such an update strategy was determined based on the operational assessment in CWB (not shown), which led to the best QPF performance. Finally, the horizontal covariance localization radius for the $w, q_{r}, q_{s}$, and $q_{g}$ were $12 \mathrm{~km}$, while that for $u, v, \theta^{\prime}$, and $q_{v}$ were $36 \mathrm{~km}$. The vertical covariance localization radius was $4 \mathrm{~km}$ for all the variables.

\subsection{The Blending Scheme}

Yang $(2005 \mathrm{a}, \mathrm{b})$ proposed a blending scheme to combine two model fields into a blending analysis based on spatial filtering technique. The concept of this blending technique could be illustrated as

$X_{\text {blend }}=\left(X-X_{s f}\right)+Y_{s f}$

where $X$ and $Y$ denote two different model fields. The subscript $s f$ means a model field whose short-wavelength ranges were filter out using spatial filtering method. In other words, $Y_{s f}$ only contains long-wavelength of its original model field $Y$. The other term $\left(X-X_{s f}\right)$ is in contrast contains only shortwavelength ranges of its original model field $X$. Finally, a blending field $X_{\text {blend }}$ is obtained by combing $\left(X-X_{s f}\right)$ and $Y_{s f}$.

The spatial filtering technique used in this study was formulated on a sixth-order tangential implicit filtering method (Raymond and Garder 1991). In this method, an empirical length scales value $(L)$ is required to determine the spectrum amplitude response $(H)$ as shown in Eqs. (2) and (3), which divided a model field into two corresponding wavelength ranges.

$H(L)=\left[1+\tan ^{6}\left(\frac{\pi \Delta x}{L}\right) / \varepsilon\right]^{-1}$ 
$\varepsilon=\tan ^{6}\left(\frac{\pi \Delta x}{l_{x}}\right)$

where $\Delta x$ is model grid spacing, which is $2 \mathrm{~km}$ in this study. $l_{x}$ is the cut-off length scale (CLS), which determines the range of short-wavelength in spatial filtering. Figure $2 \mathrm{dem}-$ onstrates the change of amplitude response (y-axis) in response to different length scales (x-axis) and several CLS values. The CLS values included 300, 450, 600, 750, and $900 \mathrm{~km}$. Here, an amplitude response value of 0 means that the model field is filtered out completely, and a value of 1 means it remains untouched. Clearly, more short-wavelength ranges are filtered out when the CLS is larger.

In this study, $X$ is the limited-area WRF model forecast, and $Y$ is the NCEP GFS analysis. That is to say; we aimed to retain only small-scale features from the high-resolution model and incorporate the large-scale features from the global model. For example, Fig. $3 \mathrm{a}$ is the $\mathrm{x}$ component of wind $(u)$ from NCEP GFS analysis. Figures $3 c$ and e are the high-resolution WRF model forecasts that refer to the background of 3DVAR and LETKF, respectively. Among them, the background of $u$ wind in LETKF (Fig. 3e) was smoother than in 3DVAR (Fig. 3c) because the LETKF background was the average over the 32 ensemble members. It shows that the wind speed in the background of 3DVAR and LETKF was significantly lower than that in the NCEP GFS analysis. Both differences were up to $4 \mathrm{~m} \mathrm{~s}^{-1}$ in the northwestern and southwestern open ocean of Taiwan. After applying spatial filtering with different CLS values, the large-scale features of the NCEP GFS analysis $\left(Y_{s f}\right)$ and the small-scale features of the 3DVAR/LETKF background $\left(X-X_{s f}\right)$ were displayed. For GFS as shown in Fig. 3b, the result used $300 \mathrm{~km}$ CLS was closest to its original GFS analysis. When the CLS increased from 300 to $900 \mathrm{~km}$, the wind perturbation became smaller and smoother. For the background of 3DVAR and LETKF as shown in Figs. 3d and $\mathrm{f}$, both wind perturbation increased with increasing CLS. Finally, the results of blending field $\left(X-X_{s f}+Y_{s f}\right.$, Figs. $\left.3 \mathrm{~g}-\mathrm{h}\right)$ showed that using $300 \mathrm{~km}$ CLS retained more information from GFS analysis, especially over the open ocean. The wind speed was up to 12 and $15 \mathrm{~m} \mathrm{~s}^{-1}$ over the southwestern and northeastern Taiwan areas. In contrast, using $900 \mathrm{~km}$ CLS kept more small-scale features from WRF, obtaining weaker and more scattered wind speed over southwestern Taiwan.

The $\mathrm{x}$ and $\mathrm{y}$ components of wind, perturbation potential temperature, water vapor mixing ratio, perturbation pressure, perturbation dry air mass, and surface pressure were included in the blending scheme. The effect of the blending scheme was similar to the $\mathrm{x}$ component of wind (Fig. 3).

In order to quantify how much information in the blending results (3g.h) was taken from GFS analysis (Fig. 3a), the correlation coefficient between the two fields was computed as Fig. 4. Since smaller CLS indicated that more GFS information was incorporated, we expected that the correlation would decrease as CLS increased. As expected, the coefficient decreased from $0.94-0.95$ at $300 \mathrm{~km}$ to $0.88-0.92$ at $900 \mathrm{~km}$. In addition, LETKF had a higher correlation than 3DVAR for all CLS, which could result from the smoother LETKF ensemble mean as shown in Fig. 3.

\subsection{The Data Assimilation Procedure}

In this study, we aimed to improve model QPF through the implementation of blending scheme in the convectivescale data assimilation system. A heavy rainfall case occurred in June 2012 under the influence of Meiyu front and strong southwesterly flow was selected. Figure 5 is the 6-hour accumulated rainfall from quantitative precipitation estimation (QPE) products, which was operational in CWB. This QPE product was derived on a regular grid with $0.0125^{\circ}$ resolution using empirical reflectivity-rainfall relation. Also, surface rainfall observations were used to correct the estimated rainfall (Wang et al. 2016). The QPE was also used for verification, as introduced in section 2.4. As shown in Fig. 5, active convection occurred in the Central Mountain Range (CMR) and southwestern part of Taiwan during 0000 UTC 10 June 2012 to 0000 UTC 11 June 2012, producing torrential rainfall more than $400 \mathrm{~mm}$ within 24 hours (not shown). Figure 6 depicts the large-scale environment at 0000 UTC 10 June 2012. Under the influence of Meiyu front, northern Taiwan was encompassed by strong horizontal wind shear with the higher equivalent potential temperature. In the pre-frontal region, strong southwesterly flow transported warm and humid air toward the island, supporting the development of convective systems mentioned above. Such vigorous convection was typical in the presence of monsoon flow (Ruppert et al. 2013), which could have a compound effect due to the terrain effect.

To evaluate the benefits of blending scheme in 3DVAR and LETKF data assimilation systems, 24 cycles with an hourly update from 00 to 23 UTC on 10 June 2012 were designed (Fig. 7). Both systems were cold-started from NCEP GFS $0.5^{\circ} \times 0.5^{\circ}$ analysis. To provide enough spin-up time, both 3DVAR and LETKF experiments went through the same data assimilation spin-up time of 12 hours. The 3DVAR system was cold-started at 12 UTC 9 June. In LET$\mathrm{KF}$, the ensemble forecasts were carried out at 06 UTC 9 June 2012 to spin up the ensemble spread, and then the data assimilation began at 12 UTC 9 June 2012. The verification period was from 00 UTC 10 June 2012 to 23 UTC 10 June 2012. The blending scheme was applied every six hours at $00,06,12,18$ UTC by combining the low-resolution NCEP GFS $0.5^{\circ} \times 0.5^{\circ}$ analysis with the high-resolution WRF background from 3DVAR systems (Fig. 8a). Similarly, in the LETKF system, the blending scheme combined the NCEP GFS analysis and the ensemble mean of the background (Fig. 8b). Therefore, the blending scheme in the LETKF system played a role similar to the recentering 


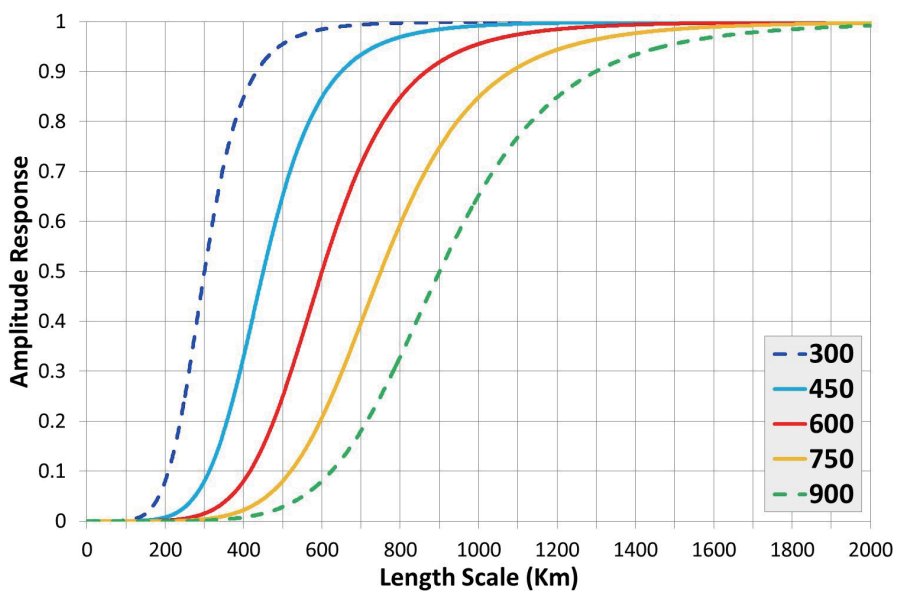

Fig. 2. The amplitude response (y-axis) corresponding to the length scales (x-axis) with the different CLS settings. The CLS values include 300 , $450,600,750$, and $900 \mathrm{~km}$.

\section{X-wind component $(\mathrm{m} / \mathrm{s})$ at Model Level 5}

(a)

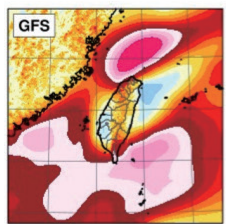

(c)

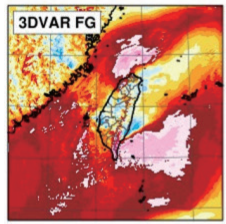

(e)

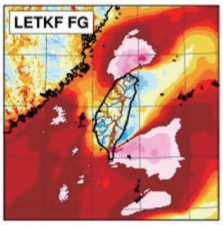

(b)

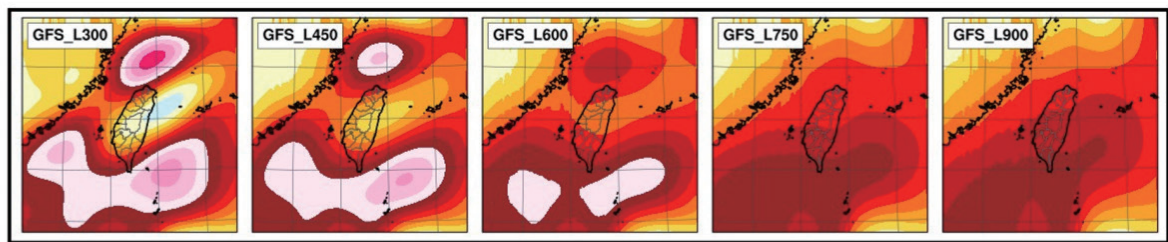

(d)

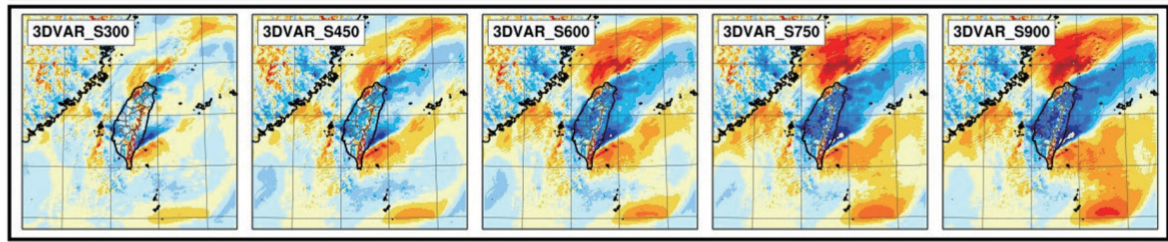

(f)

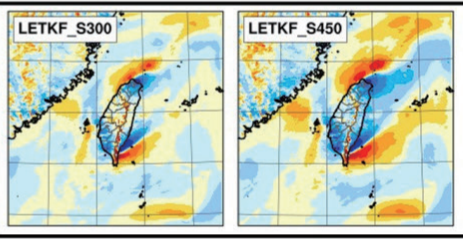

(g)
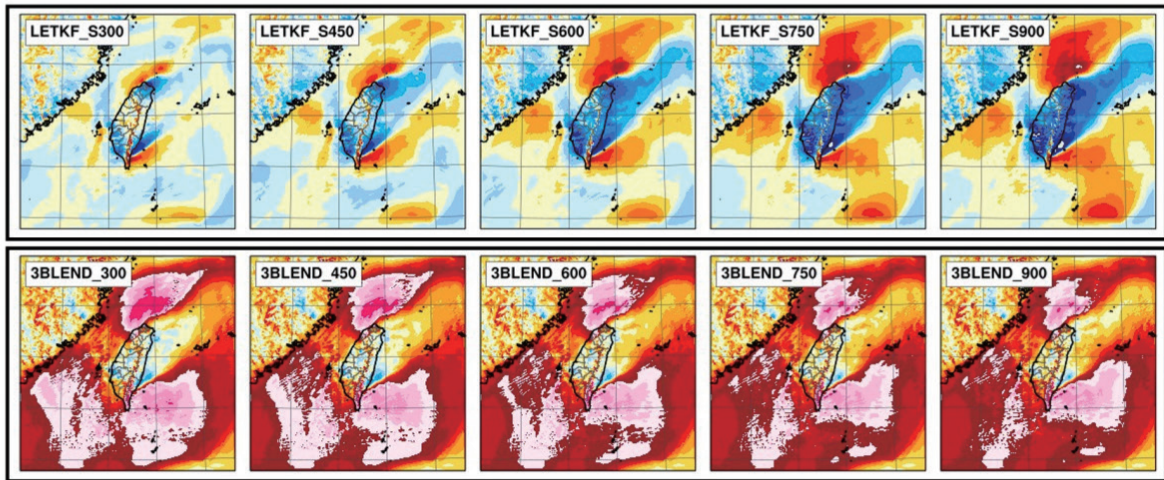

(h)
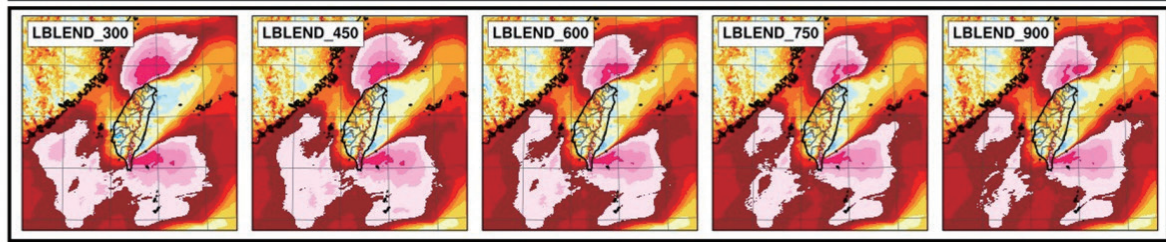

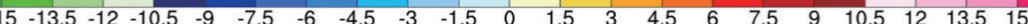

Fig. 3. The x component of wind (u) at model sigma vertical level 5 (about $220 \mathrm{~m}$ height) at 1800 UTC 09 June 2012. (b) is the large-scale features of the NCEP GFS analysis (a) from the spatial filtering with the different CLS settings, including 300, 450, 600, 750, and 900 km. Similarly, (d) and (f) are the small-scale features of the 3DVAR (c) and LETKF (f) background, respectively. Both fields correspond to $Y_{s f}$ and $\left(X-X_{s f}\right)$ in Eq. (1). Finally, both $(\mathrm{g})$ and $(\mathrm{h})$ are the blended $\mathrm{U}$ wind which is $X_{\text {blend }}$ of Eq. (1). 


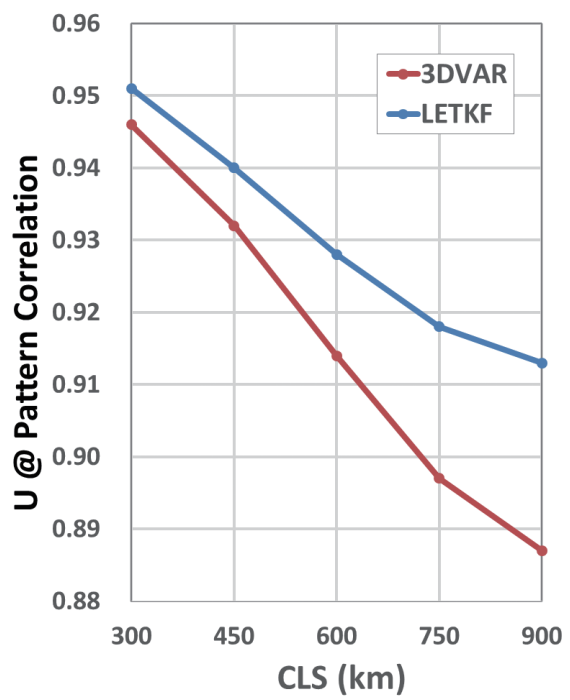

Fig. 4. The pattern correlation of GFS analysis at 1800 UTC 09 June 2012 with the different CLS (300, 450, 600, 750, and 900 km) experiments for 3DVAR (red line) and LETKF (blue line), respectively.
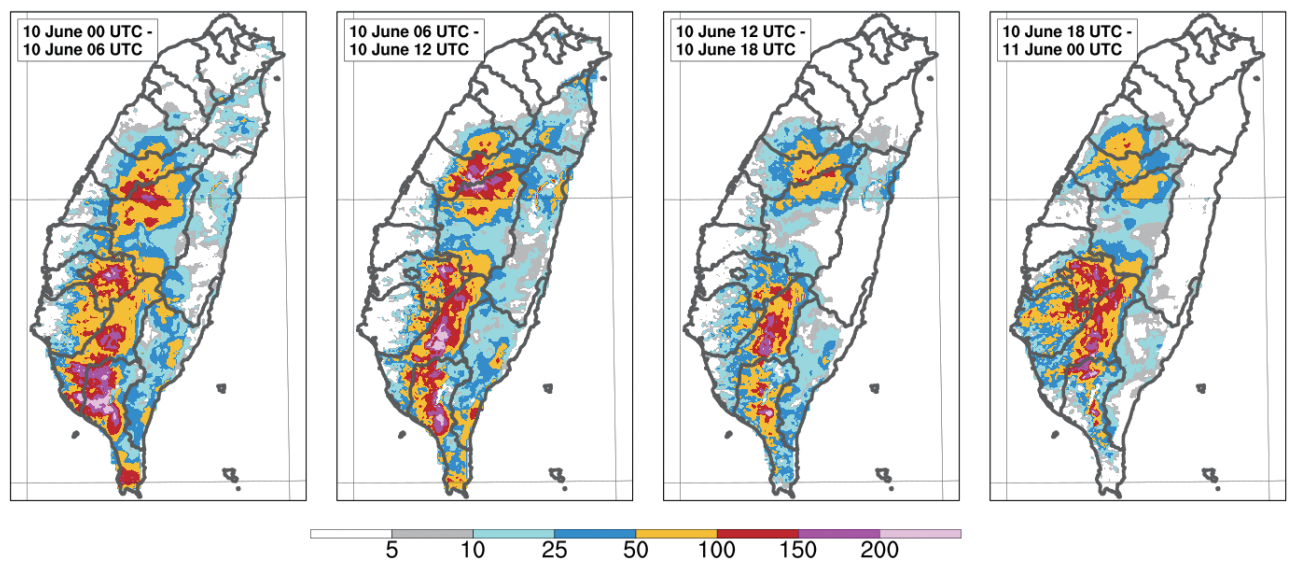

Fig. 5. The 6-hour accumulated QPE from 0000 UTC 10 June 2012 to 0000 UTC 11 June 2012.

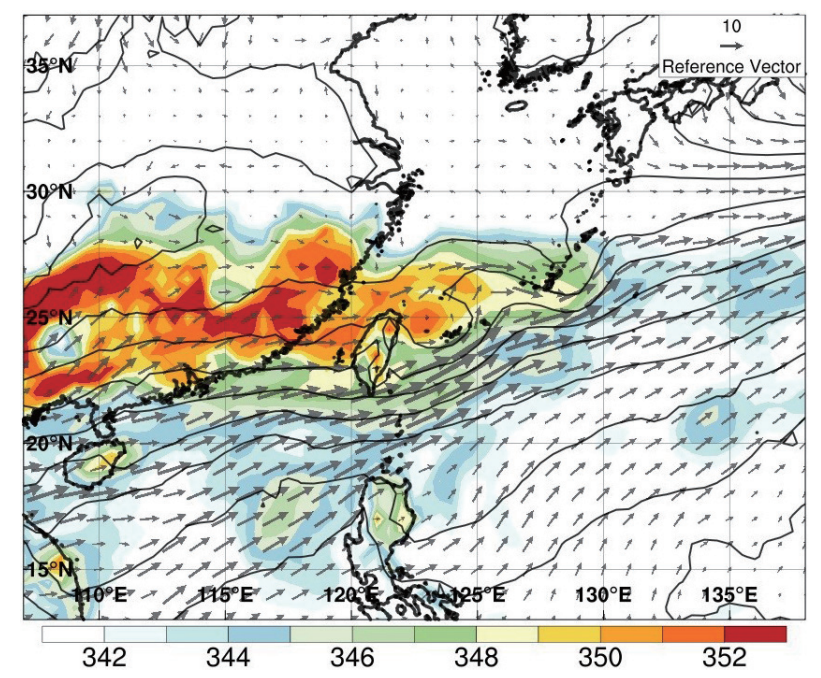

Fig. 6. The $850 \mathrm{hPa}$ analysis field of NCEP GFS at 0000 UTC 10 June 2012. The solid black lines are the geopotential height (m), the arrows are the wind speed $\left(\mathrm{m} \mathrm{s}^{-1}\right)$, and the shading means the equivalent potential temperature $(\mathrm{K})$. 


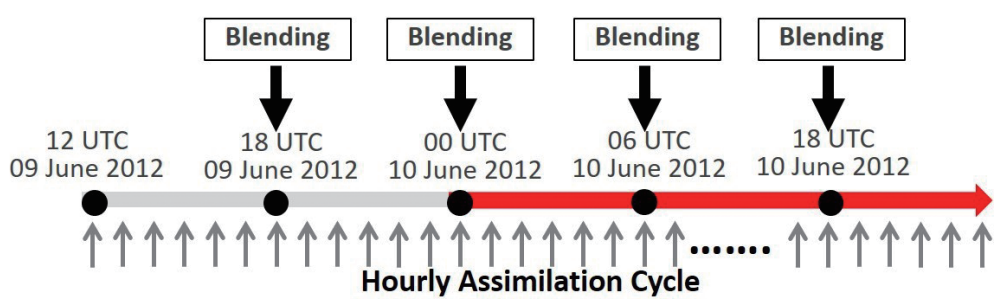

Fig. 7. The strategy of the hourly cyclic WRF 3DVAR radar data assimilation system with the blending scheme. The gray and red periods represent the spin-up and the study periods, respectively.

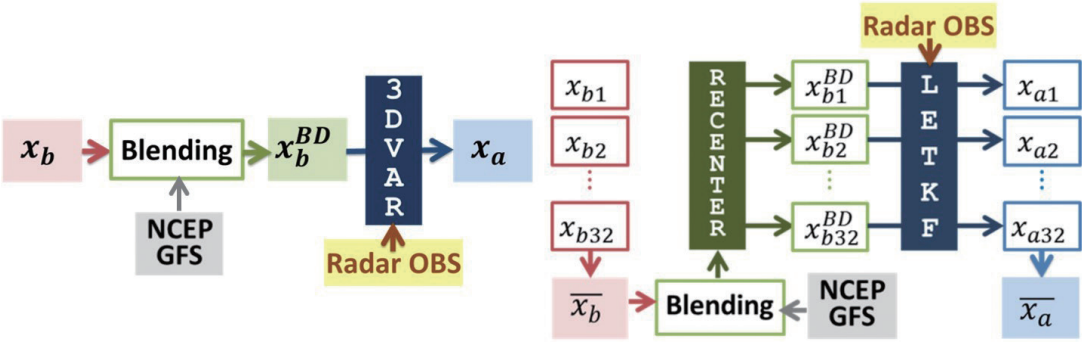

Fig. 8. The strategy of the blending scheme applies to the 3DVAR (a) and LETKF (b) radar data assimilation system. In Fig. 7a, $x_{b}$ and $x_{b}$ are the background and analysis. $x_{b}^{B D}$ is a new background after the blending scheme that was applied every six hours at 00, 06, 12, 18 UTC. In 7(b), $\overline{x_{b}}$ $\left(x_{b k}, k=1,2, \ldots, 32\right)$ and $\bar{x}_{a}\left(x_{a k}, k=1,2, \ldots, 32\right)$ are the ensemble mean (members) of the background and analysis. $x_{b k}^{B D}(k=1,2, \ldots, 32)$ are the new ensemble background after the blending scheme.

mechanism commonly used in the ensemble data assimilation (Wang et al. 2013). Sensitivity experiments were carried out to explore the impact of different CLS $(300,450$, 600,750 , and $900 \mathrm{~km}$ ) on the model QPF. The details of the experiment design were listed in Table 1.

\subsection{Rainfall Verification}

The fractions skill score (FSS; Roberts 2008) was selected to evaluate the model QPF skill. Rather than pointto-point verification, FSS is a neighborhood verification method that takes into account the spatial probability. Equations (4) and (5) are the FSS formulations.

$$
\begin{aligned}
& F S S=1-\frac{F B S}{F B S_{\text {worst }}} \\
& F B S=\frac{1}{N} \sum_{i=1}^{N}\left(P_{f}-P_{o}\right)^{2} \\
& F B S_{\text {worst }}=\frac{1}{N}\left(\sum_{i=1}^{N} P_{f}^{2}+\sum_{i=1}^{N} P_{o}^{2}\right)
\end{aligned}
$$

where $N$ is the number of model grids $(N=49$ in this study) within a predefined influence radius ( $8 \mathrm{~km}$ in this study). $P_{f}$ and $P_{o}$ are the spatial fraction of the model forecast and observation that exceed a predefined rainfall threshold. The $F B S$ value ranges from 0 to 1 , and $F B S_{\text {worst }}$ represents the largest possible FBS. Briefly, FSS of 1 indicates a perfect forecast, which means that model forecast and observation have the same spatial fraction within the influenced radius, while $F S S$ of 0 indicates no forecasting skill.

\section{RESULTS}

In this section, we first examined the impact of the blending scheme in the 3DVAR and LETKF data assimilation system using a CLS of $600 \mathrm{~km}$. To further optimize the performance of blending scheme, its sensitivity to different CLSs and blending variables were also investigated. Each experiment had a total of 24 cycles with an hourly update from 00 to 23 UTC on 10 June 2012. A total of 24 model forecasts initialized by hourly 3DVAR and LETKF analysis were used to evaluate the effect of the blending scheme.

\subsection{Impact of the Blending Scheme in Radar Data Assimilation System}

As shown in Fig. 9, there are two distinct rainfall maximums located at central (labelled as system A) and southern CMR (labelled system B) at 1900 UTC 10 June 2012. The maximum 0 - 6 hour accumulated rainfall reached 113 and $245 \mathrm{~mm}$ for system A and B, respectively. Figures $9 \mathrm{~b}$ and $\mathrm{d}$ show the corresponding rainfall predictions from 3DVAR and LETKF systems without the blending scheme. For system A, 3woBD and LwoBD had maximum accumulation rainfall of 111 and $117 \mathrm{~mm}$, respectively, which was close to the $113 \mathrm{~mm}$ of radar QPE despite the slightly scatter rainfall pattern. For system B, both experiments produced 
Table 1. Data assimilation experiment setting and description.

\begin{tabular}{cc}
\hline Experiment & Description \\
\hline 3woBD/LwoBD & Without the blending scheme \\
3BN300/LBN300 & Blending NCEP GFS analysis at CLS $=300 \mathrm{~km}$ \\
3BN450/LBN450 & Blending NCEP GFS analysis at CLS $=450 \mathrm{~km}$ \\
3BN600/LBN600 & Blending NCEP GFS analysis at CLS $=600 \mathrm{~km}$ \\
3BN750/LBN750 & Blending NCEP GFS analysis at CLS $=750 \mathrm{~km}$ \\
3BN900/LBN900 & Blending NCEP GFS analysis at CLS $=900 \mathrm{~km}$ \\
\hline
\end{tabular}

Note: $C L S$ is cut-off length scale, $L$ is for LETKF, 3 is for $3 D V A R$.

6-hr Accu. Rainfall (mm) @ 00 - 06 hr forecast Initial at 1900 UTC 10 Jun 2012 / Valid at 2012061019 - 2012061101 UTC
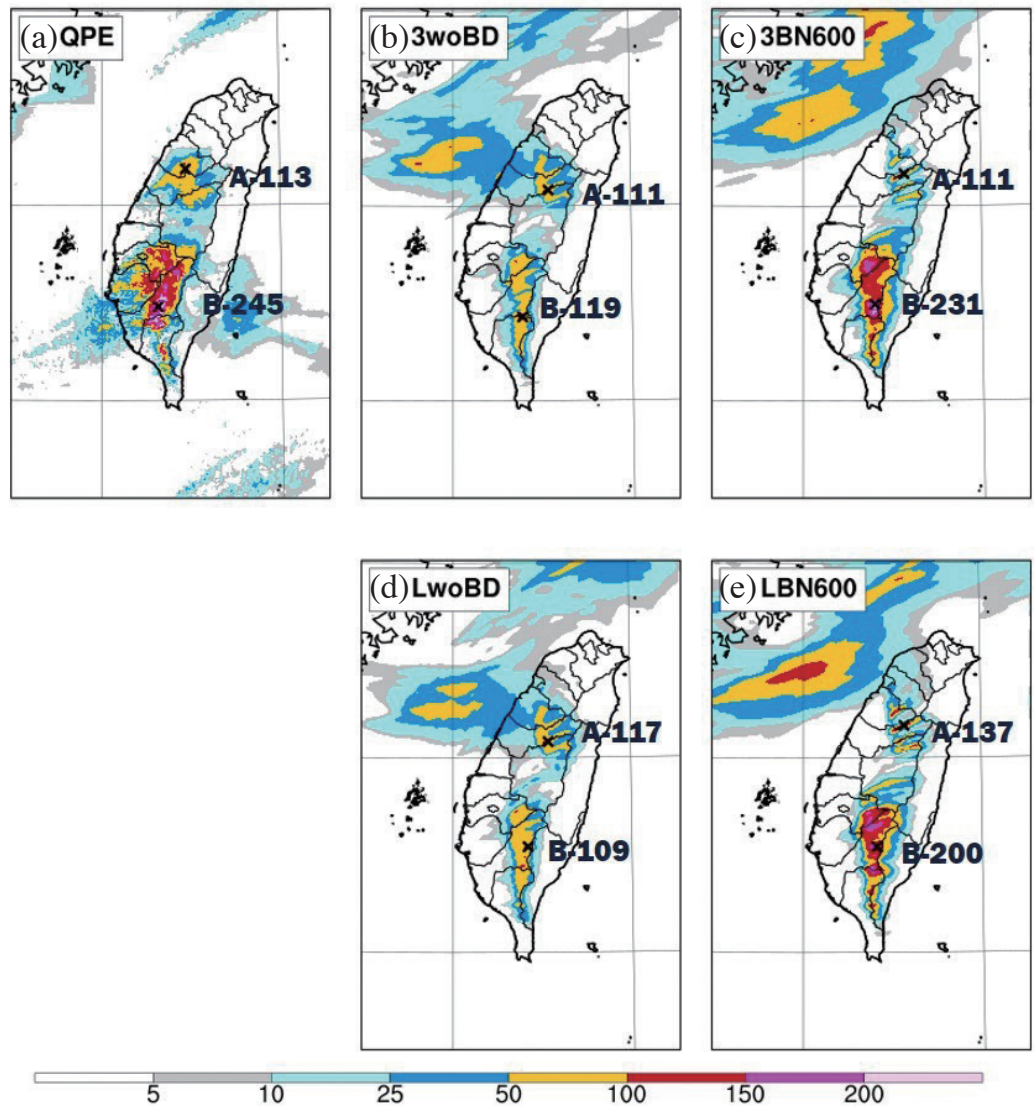

Fig. 9. The 0-6 hour accumulated rainfall from QPE (a) and experiments including 3woBD (b), 3BN600 (c), LwoBD (d), and LBN600 (e) that are described in Table 1. The initial condition is at 1900 UTC 10 June 2012. The illustration also marks the maximum precipitation values and their locations in areas $\mathrm{A}$ and $\mathrm{B}$. 
rainfall only half of the amount of radar QPE. Therefore, we aimed to investigate if the blending scheme could improve this distinct rainfall forecast error.

In comparison with 3 woBD and LwoBD, 3BN600 and LBN600 included a blending scheme with $600 \mathrm{~km}$ CLS. As shown in Figs. 9c and e, employing the blending scheme in data assimilation cycles to incorporate large scale information from NCEP GFS significantly improved the model QPF skill. In contrast to the insufficient rainfall in 3woBD and LwoBD, 3BN600 and LBN600 had 6-hour accumulated rainfall intensity closed to radar QPE. In this case, 3BD600 had a slightly better model QPF skill than LBD600.

To understand the reason why the additional blending scheme significantly elevated model QPF skill, the moisture transportation by the pre-frontal southwestly flow was investigated since it was suggested to play an important role on terrain enhanced heavy rainfall as shown in Fig. 6. Vertically integrated moisture flux convergence (VIMFC, Hudson 1970) from 1000 to $700 \mathrm{hPa}$ was calculated to quantify the amount of moisture transportation,

$\mathrm{VIFMC}=-\frac{1}{g} \int_{1000 \mathrm{hPa}}^{700 \mathrm{ha}}\left(\frac{\partial u q}{\partial x}+\frac{\partial v q}{\partial y}\right) d p$

As shown in Fig. 10, the results showed that the larger VIMFC was produced over the windward side of CMR in southern Taiwan. In general, over the southwestern ocean of Taiwan, the southerly wind component (Figs. 10c and f) and moisture (Figs. 11c and f) were increased after blending the global analysis. The stronger southerly wind was suggested due to the enhanced stronger channel effects. It accelerated the southerly wind speed as flow into the Taiwan Strait, resulting in more divergence over the open ocean. In contrast, the stronger southerly wind component also contributed more convergence over the southeastern coast of Taiwan due to the terrain effect. Combined with the moisture and the convergence field, and finally resulted in the stronger VIMFC over the southeastern coast of Taiwan and weaker VIMFC over the open ocean area.

This stronger VIMFC provided a favorable environment for the development of convections, which was consistent with the improvement of model QPF for system B in 3BN600 and LBN600 (Figs. 9c and e). In contrast, the lack of these two key features led to insufficient rainfall for system B in 3woBD and LwoBD (Figs. 9b and d). For System A, the wind speed was more parallel to the CMR. Even though the moisture (Fig. 11) increased slightly, the VIMFC only had a limited increase after blending. Therefore, the impact of the blending scheme on system A was not significant.

Although 3woBD and LwoBD both assimilated radar observation, the analysis correction over terrain and the open ocean was generally small due to the lack of correction in regions far away from radar sites or in data-void regions due to complex terrain. Also, assimilating radar reflectivity and radial velocity only corrected wind and hydrometer fields in the 3DVAR system; therefore, by no ways to correct errors in water vapor forecast. Although the LETKF system had cross-variable correlations embedded in the flow-dependent background error covariance, the correlations between water vapor and other control variables were relatively weak, which could result from model bias and sampling error due to our limited ensemble size $(\mathrm{Wu}$ et al. 2020). Therefore, this case illustrated the importance of blending large-scale information during convective-scale data assimilation cycles to remove the accumulated forecast error in the background, e.g., $\mathrm{x}$ and $\mathrm{y}$ components of wind, perturbation potential temperature and water vapor mixing ratio, which could not be corrected efficiently due to the limitation of observation and data assimilation strategy.

Average FSS over 24 forecasts were computed to evaluate the robustness of the blending strategy. In this study, we targeted improving model 0 - 6 hour QPF skill, and only precipitation over land points were included in the verification. As shown in Fig. 12, 3BN600 and LBN600 outperform their corresponding no blending experiments, especially for larger rainfall thresholds. Compared to LwoBD with 3 woBD, LETKF had higher model QPF skill than 3DVAR, which was as expected from the literature (e.g., Zhang et al. 2011) that the LETKF could be benefited from the flowdependent background error covariance. On the contrary, 3BN600 had a higher FSS than LBN600 for rainfall thresholds larger than $80 \mathrm{~mm}$ after applying the blending scheme. The impact of blending scheme was larger in 3DVAR compared with LETKF. In the LETKF system, the blending scheme was used to combine the LETKF smoothed ensemble mean and large-scale analysis, which could further aggravate the model spin-up issue resulted from the lack of small-scale structures. In contrast, it was directly applied to the 3DVAR background field which contained more convective scale features.

\subsection{Sensitivity of Blending Variables and Cut Off Length on Model QPF}

Additional 3DVAR experiments were designed to understand the relative importance of blending variables, including horizontal wind component $(u, v)$, perturbation potential temperature $\left(\theta^{\prime}\right)$, and water vapor mixing ratio $\left(q_{v}\right)$ in this case. Each experiment was comprised of 24 forecasts. As shown in Fig. 13, it is possible to classify all experiments into two groups. Obviously, experiments in which blended water vapor (BLEND_Q, BLEND_QT, BLEND_UVQ, and BLEND_UVQT) had higher model QPF skill than others, again emphasizing the key role of large-scale moisture field in this case. Ultimately, BLEND_UVQT blended all four variables and had the best QPF skill among all. It was suggested that the better QPF performance was conducive to 
Vertically Integrated Moisture Flux Convergence / Initial at 1900 UTC 10 Jun 2012
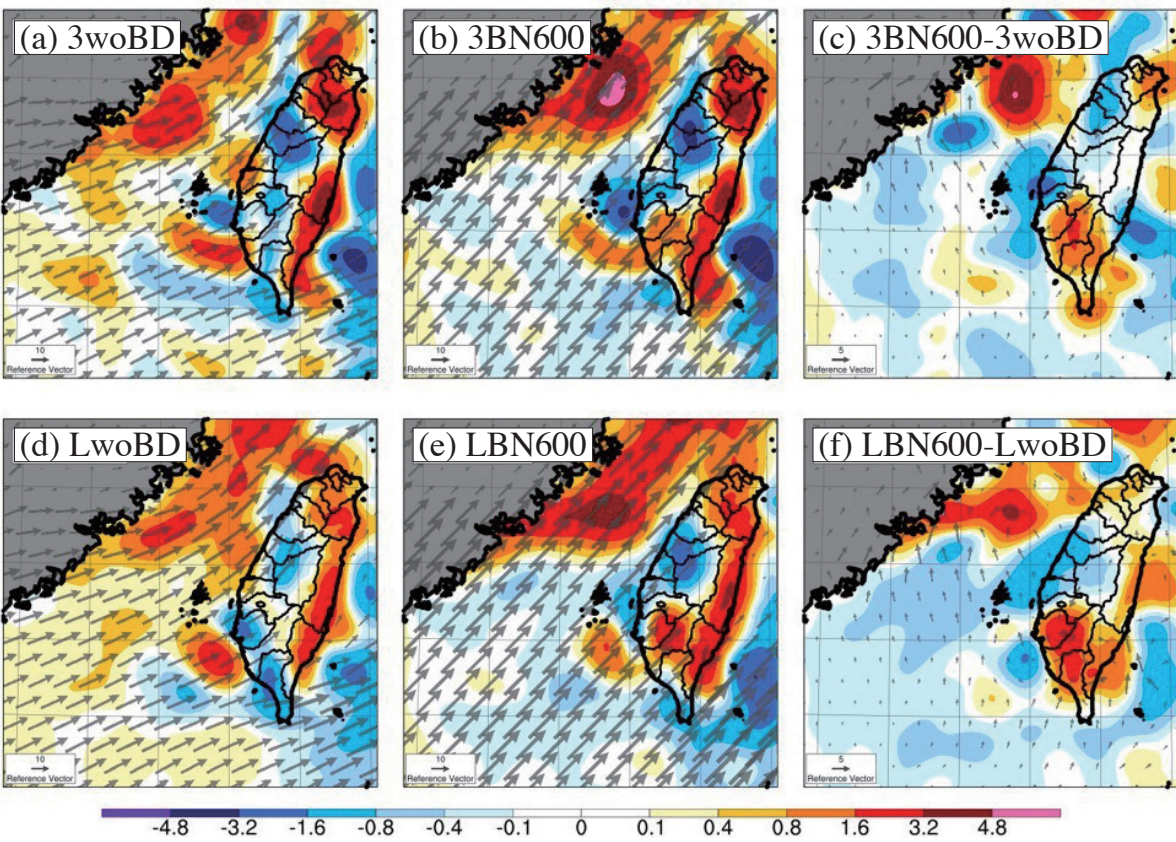

Fig. 10. The vertically integrated moisture flux convergence (VIMFC, shading, $10^{-3} \mathrm{~kg} \mathrm{~m}^{-2} \mathrm{~s}^{-1}$ ) and the $850 \mathrm{hPa}$ wind vector $\left(\mathrm{m} \mathrm{s}^{-1}\right)$ from the $3 \mathrm{woBD}$ (a), 3BN600 (b), LwoBD (d), and LBN600 (e) experiment. The vertical integration of VIMFC is from 1000 to $700 \mathrm{hPa}$. The positive/negative values of the shading are the convergence/divergence, respectively. (c) is the difference between 3BN600 and 3woBD, while (f) is the difference between LBN600 and LwoBD.

Water Vapor Mixing Ratio (g/kg) / Initial at 1900 UTC 10 Jun 2012

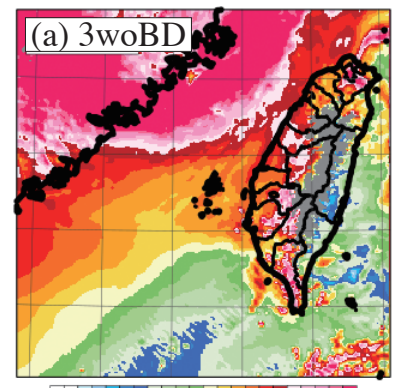

$\frac{1212.412 .813 .213 .6}{14} 1414.414 .815 .215 .616$

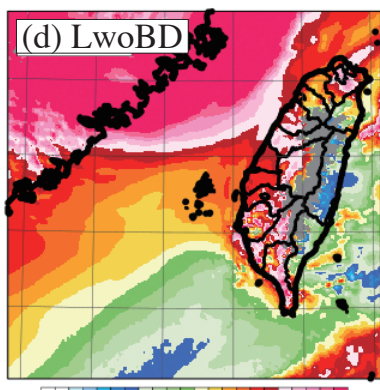

$\frac{1}{12} 12.412 .813 .213 .6 \quad 14$ 14.414.815.2 15.616
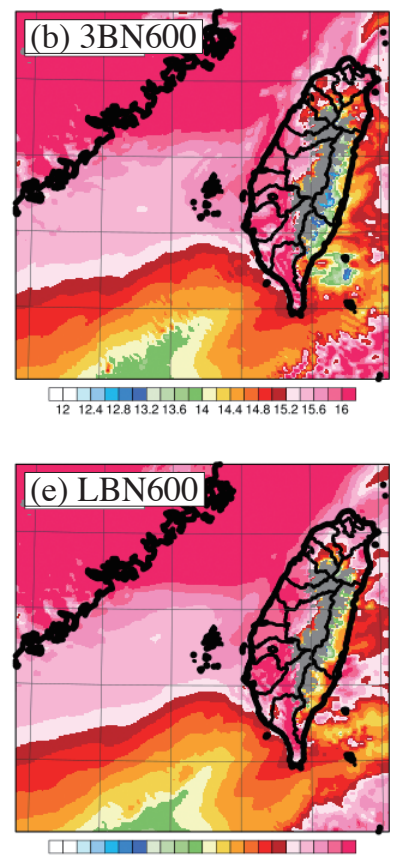

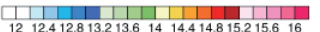
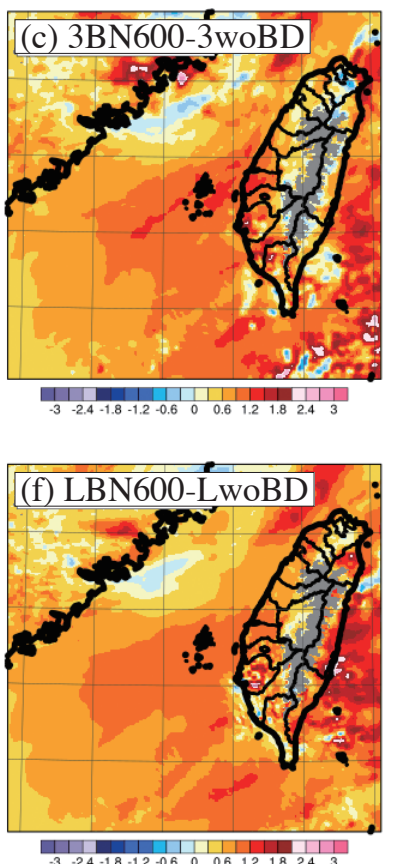

Fig. 11. The $850 \mathrm{hPa}$ water vapor mixing ratio (shading, $\mathrm{g} \mathrm{kg}^{-1}$ ) from the 3 woBD (a), 3BN600 (b), LwoBD (d), and LBN600 (e) experiment. (c) is the difference between 3BN600 and 3woBD, while (f) is the difference between LBN600 and LwoBD. 


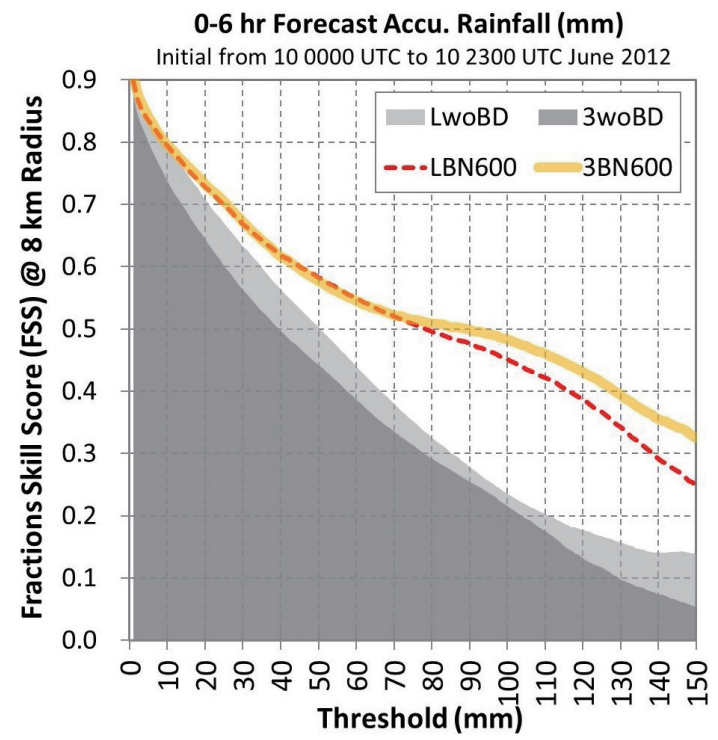

Fig. 12. The FSS of 0 - 6 hours QPF aggregates 24 forecasts from 0000 to 2300 UTC of 10 June 2012. The horizontal axis is the rainfall threshold

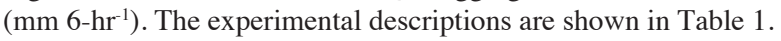

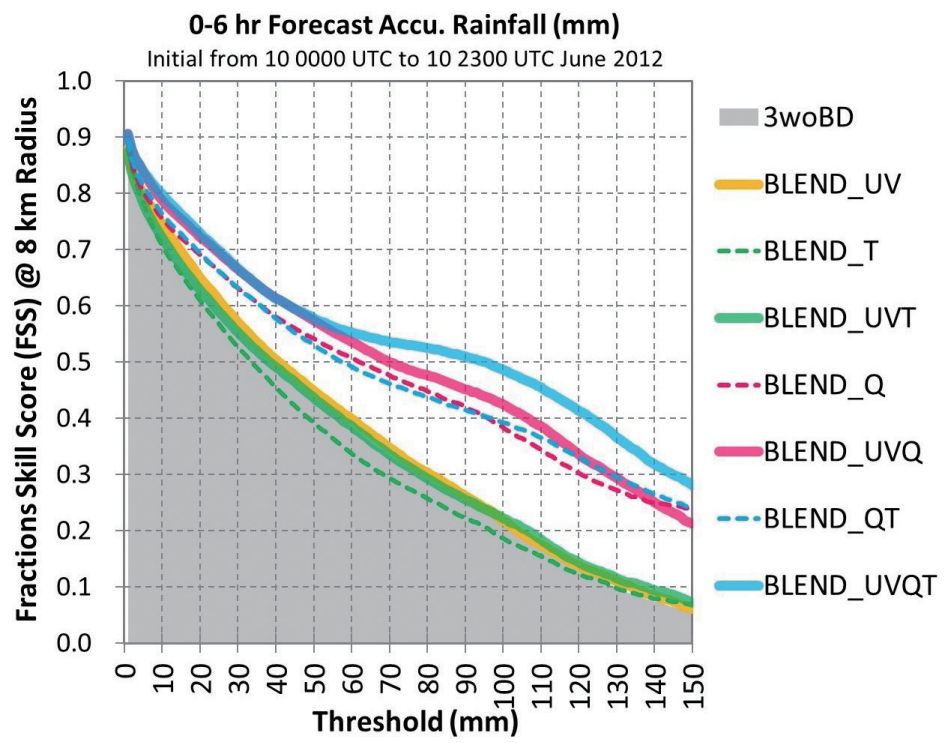

Fig. 13. Same as Fig. 12, but for the FSS of the different model variables used in blending scheme based on the 3DVAR experiments.

the more balanced meteorological fields in BLEND_UVQT, which blended all meteorological variables.

To employ the blending scheme optimally, we further investigated the sensitivities of different cut-off length scales on model QPF. CLS determined how much largescale information was introduced in a blended field. For example, a smaller CLS retained more information from GFS fields. Five different CLS experiments were conducted for 24 data assimilation cycles for each. The CLS setting included 300, 450, 600, 750, and $900 \mathrm{~km}$. Figure 14 shows that the model QPF score significantly improved both in 3DVAR and LETKF experiments as including the blend- ing scheme no matter which CLS was used. Similarly, the VIMFC had the same performance between different CLSs (not shown). All CLS experiments in 3DVAR and LETKF had captured the similar large-scale feature. Figure 14 also shows that 3DVAR had distinct FSS scores with respect to different CLS, in particular for large rainfall thresholds. However, in the LETKF system, the impact of different CLS on model QPF skill was small. As we could see in Fig. 4, it was consistent that the correlation with GFS analysis dropped more steeply with increasing CLS in 3DVAR compared with LETKF. Overall, the experiments suggested an optimal CLS of $600 \mathrm{~km}$ in this study. 

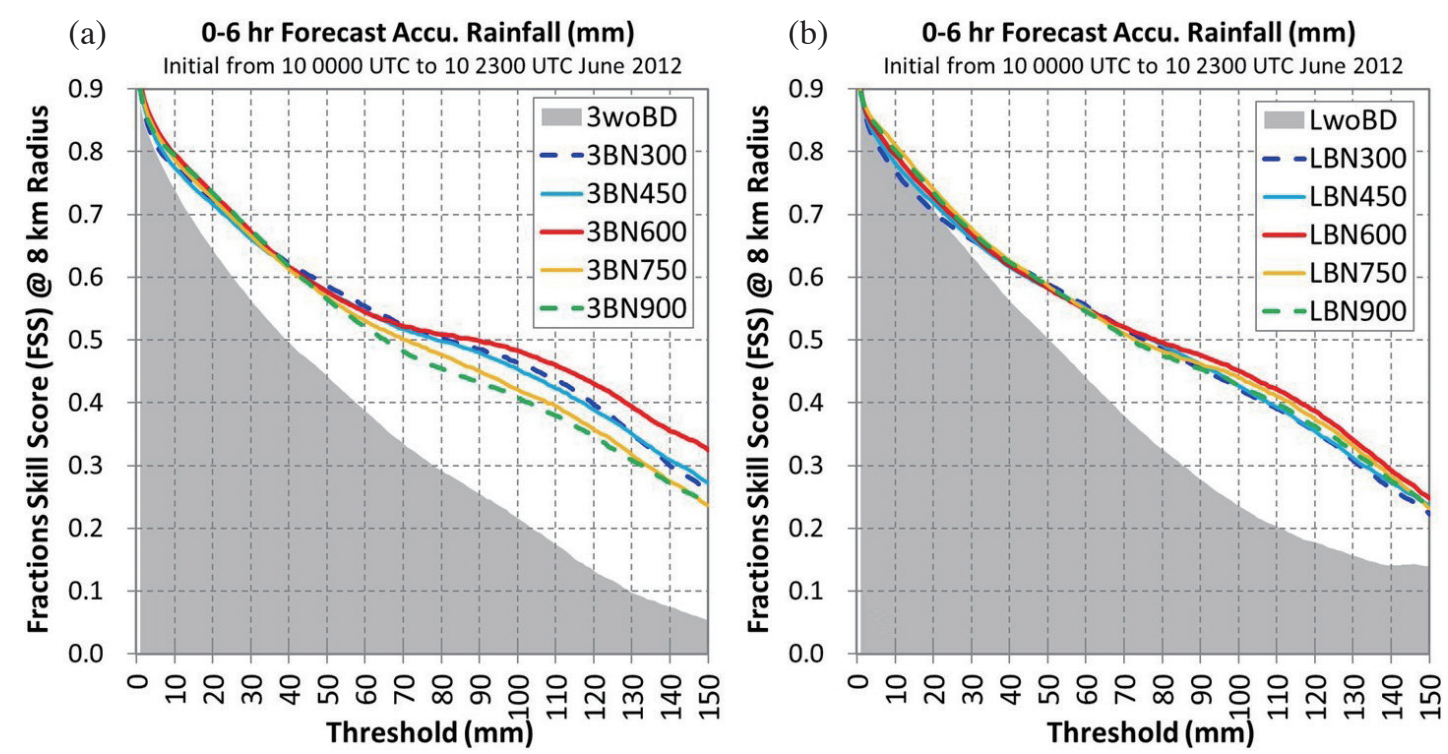

Fig. 14. The FSS of accumulation threshold (mm) aggregate all 24 forecasts starting at 0000 UTC 102012 to 2300 UTC 10 June 2012 for 0 - 6 hours QPF. The results are the (a) 3DVAR and (b) LETKF experiment using different CLS settings. The experimental descriptions are shown in Table 1.

\section{SUMMARY}

It is challenging to improve the short-term QPF accompanied with extreme rainfall, particularly for an operational center, like Taiwan's Central Weather Bureau. Several studies demonstrated that rapid-updated convective-scale data assimilation for radar and surface observations could effectively elevate the model QPF skill. However, the forecast error could accumulate with time through the long-term continuous cyclic data assimilation, especially over the data-void areas, resulting in a systematic drift from large-scale patterns. It had been demonstrated that the blending scheme, which combined the large-scale patterns of the global analysis and finer structure of the high-resolution regional model, could effectively remove systematic forecast error resulted from update cycles (Hsiao et al. 2015). However, whether the effect could be obtained in the convective-scale data assimilation system required further investigation.

In this study, the blending scheme was applied to the 3DVAR and LETKF based radar data assimilation systems. Both systems had the same model configuration with $2 \mathrm{~km}$ resolution and employed hourly update cycles to assimilate the four S-band radar observations over Taiwan Island. Twenty-four data assimilation cycles were designed for both LETKF and 3DVAR systems to evaluate the impact of the blending scheme on model QPF for a heavy rainfall event. This rainfall system was associated with the strong moist southwesterly flow and produced a maximum 6-hour accumulated rainfall up to $245 \mathrm{~mm}$ over southern Taiwan. The major findings were summarized as follows:

(1) FSS computed from 24 forecasts pointed out that an additional blending scheme significantly improved model
QPF skill of both the 3DVAR and LETKF systems, particularly for large rainfall thresholds.

(2) The blending scheme imposed a larger impact on 3DVAR than LETKF, because it was directly applied to the 3DVAR background field which contained more convective scale features compared with LETKF. In contrast, blended the smoothed LETKF ensemble mean with the GFS analysis was expected to worsen the model spin-up issue due to the smoother analysis.

(3) Among all blending variables, including wind, perturbation potential temperature, and water vapor mixing ratio, moisture played a key role in the model QPF improvement in this case. Blending large-scale information from the global model adding more moisture flux into the background favored the rainfall forecast over the southwestern part of Taiwan.

(4) Additional sensitivity experiment was designed to determine the optimal cut-off length scale (CLS). In this study, model QPF from experiments with CLS of 300, 450, 600, 750, and $900 \mathrm{~km}$ was compared. Results suggested that model QPF skill was improved compared with experiment excluding blending no matter which CLS was used. Among them, $600 \mathrm{~km}$ was the optimal CLS for our current data assimilation systems. Furthermore, 3DVAR had a larger FSS difference in response to different CLSs compared with LETKF, which again emphasized the larger impact of the blending scheme on 3DVAR.

In summary, this study successfully applied the blending scheme to a rapid-update radar data assimilation and demonstrated robust improvement for the model QPF skill. In view of such encouraging results, the blending scheme could be considered for an operational purpose. 
Acknowledgements This work was supported through the Ministry of Science and Technology of Taiwan under Grant MOST 109-2625-M-052-003 and 109-2119-M-002-016. We would like to thank the Meteorology Information Center at CWB for providing the high-performance computing resources.

\section{REFERENCES}

Askelson, M. A., J.-P. Aubagnac, and J. M. Straka, 2000: An adaptation of the Barnes filter applied to the objective analysis of radar data. Mon. Weather Rev., 128, 30503082, doi: 10.1175/1520-0493(2000)128<3050:AAO TBF> 2.0.CO;2. [Link]

Barker, D., X.-Y. Huang, Z. Liu, T. Auligné, X. Zhang, S. Rugg, R. Ajjaji, A. Bourgeois, J. Bray, Y. Chen, M. Demirtas, Y.-R. Guo, T. Henderson, W. Huang, H.-C. Lin, J. Michalakes, S. Rizvi, and X. Zhang, 2012: The Weather Research and Forecasting Model's Community Variational/Ensemble Data Assimilation System: WRFDA. Bull. Amer. Meteorol. Soc., 93, 831-843, doi: 10.1175/BAMS-D-11-00167.1. [Link]

Benjamin, S. G., S. S. Weygandt, J. M. Brown, M. Hu, C. R. Alexander, T. G. Smirnova, J. B. Olson, E. P. James, D. C. Dowell, G. A. Grell, H. Lin, S. E. Peckham, T. L. Smith, W. R. Moninger, J. S. Kenyon, and G. S. Manikin, 2016: A North American hourly assimilation and model forecast cycle: The Rapid Refresh. Mon. Weather Rev., 144, 1669-1694, doi: 10.1175/MWRD-15-0242.1. [Link]

Bick, T., C. Simmer, S. Trömel, K. Wapler, H.-J. H. Franssen, K. Stephan, U. Blahak, C. Schraff, H. Reich, Y. Zeng, and R. Potthast, 2016: Assimilation of 3D radar reflectivities with an ensemble Kalman filter on the convective scale. Q. J. R. Meteorol. Soc., 142, 14901504, doi: 10.1002/qj.2751. [Link]

Cha, D.-H. and D.-K. Lee, 2009: Reduction of systematic errors in regional climate simulations of the summer monsoon over East Asia and the western North Pacific by applying the spectral nudging technique. J. Geophys. Res., 114, D14108, doi: 10.1029/2008JD011176. [Link]

Chang, P.-L., P.-F. Lin, B. J.-D. Jou, and J. Zhang, 2009: An application of reflectivity climatology in constructing radar hybrid scans over complex terrain. J. Atmos. Ocean. Technol., 26, 1315-1327, doi: 10.1175/2009JTECHA1162.1. [Link]

Chen, I.-H., J.-S. Hong, Y.-T. Tsai, and C.-T. Fong, 2020: Improving afternoon thunderstorm prediction over Taiwan through 3DVar-based radar and surface data assimilation. Weather Forecast., 35, 2603-2620, doi: 10.1175/WAF-D-20-0037.1. [Link]

Cheng, H.-W., S.-C. Yang, Y.-C. Liou, and C.-S. Chen, 2020: An investigation of the sensitivity of predict- ing a severe rainfall event in Northern Taiwan to the upstream condition with a WRF-based radar data assimilation system. SOLA, 16, 97-103, doi: 10.2151/ sola.2020-017. [Link]

Dowell, D. C., L. J. Wicker, and C. Snyder, 2011: Ensemble Kalman filter assimilation of radar observations of the 8 May 2003 Oklahoma City supercell: Influences of reflectivity observations on storm-scale analyses. Mon. Weather Rev., 139, 272-294, doi: 10.1175/2010MWR3438.1. [Link]

Feng, J., J. Sun, and Y. Zhang, 2020: A Dynamic Blending Scheme to Mitigate Large-Scale Bias in Regional Models. J. Adv. Model. Earth Syst., 12, 001754, doi: 10.1029/2019MS001754. [Link]

Gao, J. and D. J. Stensrud, 2012: Assimilation of reflectivity data in a convective-scale, cycled 3DVAR framework with hydrometeor classification. J. Atmos. Sci., 69, 1054-1065, doi: 10.1175/JAS-D-11-0162.1. [Link]

Gustafsson, N., T. Janjić, C. Schraff, D. Leuenberger, M. Weissmann, H. Reich, P. Brousseau, T. Montmerle, E. Wattrelot, A. Bučánek, M. Mile, R. Hamdi, M. Lindskog, J. Barkmeijer, M. Dahlbom, B. Macpherson, S. Ballard, G. Inverarity, J. Carley, C. Alexander, D. Dowell, S. Liu, Y. Ikuta, and T. Fujita, 2018: Survey of data assimilation methods for convective-scale numerical weather prediction at operational centres. $Q$. J. R. Meteorol. Soc., 144, 1218-1256, doi: 10.1002/ qj.3179. [Link]

Hohenegger, C. and C. Schär, 2007: Atmospheric predictability at synoptic versus cloud-resolving scales. Bull. Amer. Meteorol. Soc., 88, 1783-1794, doi: 10.1175/ BAMS-88-11-1783. [Link]

Hong, S.-Y., Y. Noh, and J. Dudhia, 2006: A new vertical diffusion package with an explicit treatment of entrainment processes. Mon. Weather Rev., 134, 2318-2341, doi: 10.1175/MWR3199.1. [Link]

Hsiao, L.-F., X.-Y. Huang, Y.-H. Kuo, D.-S. Chen, H. Wang, C.-C. Tsai, T.-C. Yeh, J.-S. Hong, C.-T. Fong, and C.-S. Lee, 2015: Blending of global and regional analyses with a spatial filter: Application to typhoon prediction over the western North Pacific Ocean. Weather Forecast., 30, 754-770, doi: 10.1175/WAFD-14-00047.1. [Link]

Hudson, H.R., 1970: On the relationship between horizontal moisture convergence and convective cloud formation. ESSA Technical Memorandum ERLTM-NSSL 45, National Severe Storms Laboratory, Norman, Oklahoma, 29 pp.

Hunt, B. R., E. J. Kostelich, and I. Szunyogh, 2007: Efficient data assimilation for spatiotemporal chaos: A local ensemble transform Kalman filter. Physica D, 230, 112-126, doi: 10.1016/j.physd 2006.11.008. [Link]

Iacono, M. J., J. S. Delamere, E. J. Mlawer, M. W. Shephard, S. A. Clough, and W. D. Collins, 2008: Radiative 
forcing by long-lived greenhouse gases: Calculations with the AER radiative transfer models. J. Geophys. Res., 113, D13103, doi: 10.1029/2008JD009944. [Link]

Kong, R., M. Xue, and C. Liu, 2018: Development of a hybrid En3DVar data assimilation system and comparisons with 3DVar and EnKF for radar data assimilation with observing system simulation experiments. Mon. Weather Rev., 146, 175-198, doi: 10.1175/MWRD-17-0164.1. [Link]

Liu, S., G. DiMego, S. Guan, V. K. Kumar, D. Keyser, Q. Xu, K. Nai, P. Zhang, L. Liu, J. Zhang, K. Howard, and J. Ator, 2016: WSR-88D radar data processing at NCEP. Weather Forecast., 31, 2047-2055, doi: 10.1175/WAF-D-16-0003.1. [Link]

Michalakes, J., S. Chen, J. Dudhia, L. Hart, J. Klemp, J. Middlecoff, and W. Skamarock, 2001: Development of a next-generation regional weather research and forecast model. In: Zwieflhofer, W. and N. Kreitz (Eds.), Developments in Teracomputing: Proceedings of the Ninth ECMWF Workshop on the Use of High Performance Computing in Meteorology, World Scientific, 269-276, doi: 10.1142/9789812799685_0024. [Link]

Miyoshi, T., M. Kunii, J. Ruiz, G.-Y. Lien, S. Satoh, T. Ushio, K. Bessho, H. Seko, H. Tomita, and Y. Ishikawa, 2016: "Big Data Assimilation" revolutionizing severe weather prediction. Bull.Amer.Meteorol.Soc.,97, 1347-1354, doi: 10.1175/BAMS-D-15-00144.1. [Link]

Raymond, W. H. and A. Garder, 1991: A review of Recursive and Implicit Filters. Mon. Weather Rev., 119, 477495, doi: 10.1175/1520-0493(1991)119<0477:AROR $\mathrm{AI}>2.0 . \mathrm{CO} ; 2$. [Link]

Ridal, M. and M. Dahlbom, 2017: Assimilation of multinational radar reflectivity data in a mesoscale model: A proof of concept. J. Appl. Meteorol. Climatol., 56, 1739-1751, doi: 10.1175/JAMC-D-16-0247.1. [Link]

Roberts, N., 2008: Assessing the spatial and temporal variation in the skill of precipitation forecasts from an NWP model. Meteorol. Appl., 15, 163-169, doi: 10.1002/ met.57. [Link]

Ruppert, J. H., R. H. Johnson, and A. K. Rowe, 2013: Diurnal circulations and rainfall in Taiwan during SoWMEX/TiMREX (2008). Mon. Weather Rev., 141, 3851-3872, doi: 10.1175/MWR-D-12-00301.1. [Link]

Sun, J. and N. A. Crook, 1997: Dynamical and microphysical retrieval from Doppler radar observations using a cloud model and its adjoint. Part I: Model development and simulated data experiments. J. Atmos. Sci., 54, 16421661, doi: 10.1175/1520-0469(1997)054<1642:DAMRFD > 2.0.CO;2. [Link]

Sun, J. and Y. Zhang, 2008: Analysis and prediction of a squall line observed during IHOP using multiple WSR-88D observations. Mon. Weather Rev., 136, 2364-2388, doi: 10.1175/2007MWR2205.1. [Link]
Sun, J., M. Xue, J. W. Wilson, I. Zawadzki, S. P. Ballard, J. Onvlee-Hooimeyer, P. Joe, D. M. Barker, P.-W. Li, B. Golding, M. Xu, and J. Pinto, 2014: Use of NWP for nowcasting convective precipitation: Recent progress and challenges. Bull. Amer. Meteorol. Soc., 95, 409426, doi: 10.1175/BAMS-D-11-00263.1. [Link]

Sun, J., H. Wang, W. Tong, Y. Zhang, C.-Y. Lin, and D. $\mathrm{Xu}, 2016$ : Comparison of the Impacts of Momentum Control Variables on High-Resolution Variational Data Assimilation and Precipitation Forecasting. Mon. Weather Rev., 144, 149-169, doi: 10.1175/MWRD-14-00205.1. [Link]

Tao, W.-K., D. Wu, S. Lang, J.-D. Chern, C. Peters-Lidard, A. Fridlind, and T. Matsui, 2016: High-resolution NUWRF simulations of a deep convective-precipitation system during MC3E: Further improvements and comparisons between Goddard microphysics schemes and observations. J. Geophys. Res., 121, 1278-1305, doi: 10.1002/2015JD023986. [Link]

Tewari, M., F. Chen, W. Wang, J. Dudhia, M. A. LeMone, K. Mitchell, M. Ek, G. Gayno, J. Wegiel, and R. H. Cuenca, 2004: Implementation and verification of the unified NOAH land surface model in the WRF model. 20th Conference on Weather Analysis and Forecasting/16th Conference on Numerical Weather Prediction, American Meteorological Society, Seattle, WA, US.

Tong, W., G. Li, J. Sun, X. Tang, and Y. Zhang, 2016: Design strategies of an hourly update 3DVAR data assimilation system for improved convective forecasting. Weather Forecast., 31, 1673-1695, doi: 10.1175/ WAF-D-16-0041.1. [Link]

Tsai, C.-C., S.-C. Yang, and Y.-C. Liou, 2014: Improving quantitative precipitation nowcasting with a local ensemble transform Kalman filter radar data assimilation system: Observing system simulation experiments. Tellus Ser. A-Dyn. Meteorol. Oceanol., 66, 21804, doi: 10.3402/tellusa.v66.21804. [Link]

Vincent, C. L. and A. N. Hahmann, 2015: The impact of grid and spectral nudging on the variance of the nearsurface wind speed. J. Appl. Meteorol. Climatol., 54, 1021-1038, doi: 10.1175/JAMC-D-14-0047.1. [Link]

Wang, H., X.-Y. Huang, D. Xu, and J. Liu, 2014: A scaledependent blending scheme for WRFDA: Impact on regional weather forecasting. Geosci. Model Dev., 7, 1819-1828, doi: 10.5194/gmd-7-1819-2014. [Link]

Wang, X., D. Parrish, D. Kleist, and J. Whitaker, 2013: GSI 3DVar-Based Ensemble-Variational Hybrid Data Assimilation for NCEP Global Forecast System: SingleResolution Experiments. Mon. Weather Rev., 141, 4098-4117, doi: 10.1175/MWR-D-12-00141.1. [Link]

Wang, Y., J. Zhang, P.-L. Chang, C. Langston, B. Kaney, and L. Tang, 2016: Operational C-band dual-polarization radar QPE for the subtropical complex 
terrain of Taiwan. Adv. Meteorol., 2016, 1-15, doi: 10.1155/2016/4294271. [Link]

Westra, S., H. J. Fowler, J. P. Evans, L. V. Alexander, P. Berg, F. Johnson, E. J. Kendon, G. Lenderink, and N. M. Roberts, 2014: Future changes to the intensity and frequency of short-duration extreme rainfall. Rev. Geophys., 52, 522-555, doi: 10.1002/2014RG000464. [Link]

Wu, P.-Y., S.-C. Yang, C.-C. Tsai, and H.-W. Cheng, 2020: convective-scale sampling error and its impact on the ensemble radar data assimilation system: A case study of a heavy rainfall event on 16 June 2008 in Taiwan. Mon. Weather Rev., 148, 3631-3652, doi: 10.1175/ MWR-D-19-0319.1. [Link]

Xiao, Q., Y.-H. Kuo, J. Sun, W.-C. Lee, D. M. Barker, and E. Lim, 2007: An approach of radar reflectivity data assimilation and its assessment with the inland QPF of Typhoon Rusa (2002) at Landfall. J. Appl. Meteorol. Climatol., 46, 14-22, doi: 10.1175/JAM2439.1. [Link]

Xue, M., F. Kong, K. W. Thomas, Y. Wang, K. Brewster, J. Gao, X. Wang, S. J. Weiss, A. J. Clark, J. S. Kain, M. C. Coniglio, J. Du, T. L. Jensen, and Y. H. Kuo, 2010: CAPS realtime storm scale ensemble and high resolution forecasts for the NOAA Hazardous Weather Testbed 2010 Spring Experiment. 25th Conference on Severe Local Storms, Denver, CO, American Meteorological Society.

Yang, S.-C., M. Corazza, A. Carrassi, E. Kalnay, and T. Miyoshi, 2009: Comparison of local ensemble transform Kalman filter, 3DVAR, and 4DVAR in a quasigeostrophic model. Mon. Weather Rev., 137, 693-709, doi: 10.1175/2008MWR2396.1. [Link]

Yang, S.-C., Z.-M. Huang, C.-Y. Huang, C.-C. Tsai, and T.-K. Yeh, 2020: A case study on the impact of ensemble data assimilation with GNSS-zenith total delay and radar data on heavy rainfall prediction. Mon. Weather Rev., 148, 1075-1098, doi: 10.1175/MWRD-18-0418.1. [Link]

Yang, X., 2005a: Analysis blending using spatial filter in grid-point model coupling. HIRLAM Newsletter, 48, 49-55.

Yang, X., 2005b: Background blending using an incremental spatial filter. HIRLAM Newsletter, 49, 3-11.

Yano, J.-I., M. Z. Ziemiański, M. Cullen, P. Termonia, J. Onvlee, L. Bengtsson, A. Carrassi, R. Davy, A. Deluca, S. L. Gray, V. Homar, M. Köhler, S. Krichak, S. Michaelides, V. T. J. Phillips, P. M. M. Soares, and A. A. Wyszogrodzki, 2018: Scientific challenges of convective-scale numerical weather prediction. Bull. Amer. Meteorol. Soc., 99, 699-710, doi: 10.1175/ BAMS-D-17-0125.1. [Link]

You, C.-R., K.-S. Chung, and C.-C. Tsai, 2020: Evaluating the Performance of a Convection-Permitting Model by Using Dual-Polarimetric Radar Parameters: Case Study of SoWMEX IOP8. Remote Sens., 12, 3004, doi: 10.3390/rs12183004. [Link]

Zhang, M., F. Zhang, X.-Y. Huang, and X. Zhang, 2011: Intercomparison of an ensemble Kalman filter with three- and four-dimensional variational data assimilation methods in a limited-area model over the month of June 2003. Mon. Weather Rev., 139, 566-572, doi: 10.1175/2010MWR3610.1. [Link] 